\title{
Universities' visual image and Internet communication
}

\author{
Gulnafist Okushova ${ }^{1, a}$, Yuliya Stakhovskaya ${ }^{1}$ and Pavel Sharaev ${ }^{2}$ \\ ${ }^{1}$ Tomsk State University, 634050 Lenin Avenue, 36, Tomsk, Russia \\ ${ }^{2}$ Tomsk Polytechnic University, 634050 Lenin Avenue, 30, Tomsk, Russia
}

\begin{abstract}
Universities of the 21st century are built on digital walls and on the Internet foundation. Their "real virtuality" of M. Castells is represented by information and communication flows that reflect various areas: education, research, culture, leisure, and others. The visual image of a university is the bridge that connects its physical and digital reality and identifies it within the information flow on the Internet. Visual image identification on the Internet and the function that the visual image performs as an electronic communication tool lay the foundation for our research. The key focal point of a university's visual image on the Internet is its official website. Our research shows that with the development of computer technology, the semantic heterogeneity of universities' visual images has changed from Web 1.0 to Web 2.0. A university's web portal both reflects and produces its digital life, which is broader and more informative than the physical life alone, as there are no temporal and spatial boundaries in electronic interactions. Polysemy and directed communication through university's visual images are effective developments for both online and offline communication for the university. The Internet communication reach all spheres of university life and reflect its content. Visual images of universities, based on electronic communication tools, not only "open" them for digital natives and digital immigrants, but also create a cyberspace for scientific and educational discourse.
\end{abstract}

\section{Introduction}

Active transfer of vital human interests to the Internet, including education, gives the university of the 21 st century no choice. The university must build upon "digital walls and foundations" in "the Internet Galaxy" of M. Castells, otherwise it will fall into oblivion [1]. Informatization of society and internetization of the electronic identification of the university are aspects of the overall discourse about this transformation. The incredible and radical nature of the challenges of our times accentuates the problem of the university image, its mission, and its objectives. "Death and revival of the University" was the topic of R. Barnett's inaugural professorial lecture delivered at London University Institute of Education on 25 October, 1997 [2]. Among those who write about the crisis of the "classical university" and the need to discover and study its new model are Lyotard, Readings and others [3, 4]. Researchers note that the university transformation is caused by the market environment, globalization of higher education, and the mobility of young "digital natives", as well as by developments in the information and communication technologies [5].
Competition among universities now takes place in cyberspace on the platforms of search and rating systems, on social networking sites and forums, in scientific and educational portals, and in convergent media. Electronic communication is used to virtually present information to the public, changing the forms and methods of the physical interaction between the university and its audience in real time. The university electronic office has become the digital reality that complements today's physical reality. The official website of the university, as its official representation on the Internet, provides it with a "place" in the global network, providing an open and accessible image. This is the basic condition for the development of both online and offline university communication. The bridge between the physical and digital reality of the University is its visual image. This permits one to identify the university through the Internet information flow.

\section{Materials and methods}

The theoretical basis for the study of the visual image of the university on the Internet came from concepts that relate to the "visual/iconic turn". Visuality is a key central concept in social and humanitarian studies in the

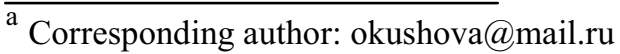


second half of the 20th century. Today, it is one of the most productive concepts in description of contemporary social and cultural reality. Researchers argue that the development of the media, such as photography, film, and television, has led to the situation when a visual image becomes the dominant means of social communication [6].

In the age of information, spatial and cyberspace communication can no longer be seen without relying on the visual image. This is most clearly manifested in the development of "new media" - computer technologies facilitating interactive communication on the Internet, corporate portals, blogs, applications for mobile devices, and social networks, which include Facebook, VKontakte, My World, and Twitter. Today universities actively "submerge" into this communicative environment because of a number of reasons, including the need to improve their position in the world university ranking and the need to apply new educational technologies meeting modern sociocultural tendencies $[7,8,9]$.

In this study, the Internet communication as a phenomenon of the global network was analysed, allowing us to formulate or identify the main characteristics of the visual nature of the Internet communication. The official website of the University was specified as a generator of the visual Internet communications. This incorporates linking a virtual space with a physical one. For the university, its presence on the website is equivalent to its existence in physical reality, bringing the university into "real virtuality" [1].

The website represents the visual image of the university. To understand this process we utilized the retrospective method. It allows us to describe the evolution of the website and to determine the technologies used for creation of the visual image.

A communication audit of the website was utilized as a principal method of research. It provided the answer to the main question of the research: is visual image a key tool of electronic communication for the university? The objects of the online communication audit were the official websites of National Research Tomsk State University (NR TSU) and National Research Tomsk Polytechnic University (NR TPU).

The online communication audit served as a comprehensive evaluation of the state of the electronic communications of the two universities with their external audiences (entrants, trustees, alumni, employers, representatives of government, traditional and new media expert scientific societies, and professional societies) and internal audience (students, staff, teachers, and members of their families).

The objects of the online communication audit were:

1. graphic visual communication;

2. the university online content; and

3. the structure of the university website and its navigation.

\section{Results and discussion}

Theoretical analysis of the Internet communication as a phenomenon of the global network allowed us to identify a number of characteristics:

- information is visually transmitted more quickly and succinctly than it is by verbal means, and supplemental video and graphics are always added to the electronic text;

- ability of the visual image to respond to communicators' interests and capabilities, as users can not be physically present in the global network;

- multiple subjects of communication serve as a fundamental change in the nature of interaction between communicators, with all participants having ability to initiate communication; and

- variability of models of communication: "one-to-one", "one-to-many", "many-to-one", or "many-to-many".

With the development of the Internet, universities became social actors in a complex and decentralized information and communication environment. Gradually universities came to understanding that they needed not only to be represented in the network, but also to maximize the use of its resources for development.

The university, as a subject of the Internet communication, needs visual imagery to work effectively with the electronic public - consumers, competitors, government bodies, partners, investors, and media - all who are now represented in the communication space of the web.

With the development of computer technology that brought the transition from Web 1.0 to Web 2.0, websites of organizations have improved. Evolution of the visual image of the university indicates that "yesterday" it had a static website focused on a small audience. With the help of Web 2.0 services, full-fledged features are possible on the Internet. The university website now is an information-rich web portal that has several language versions, an extensive navigation system, and links with social networks.

The online communication audit of official websites of Tomsk National Research Universities NR TSU and NR TPU, conducted in spring 2014, has obtained the following results.

1. The website of NR TSU (http://www.tsu.ru) contains all the elements of graphic visual communications. The logo is a simple graphical representation of the old University building, what contributes to its recognition and memorialization. It is made in blue and white colours and placed in the upper left corner. The frame of the logo is square.

The NR TSU website design is made in four basic colours - white, black, blue, and orange. The white background efficiently highlights the most significant pieces of information. Black font in combination with the white background makes reading easier. Blue colour highlights inlays on the main slider. Orange is additional and used as a highlighter. The website design weakness is that the web icons are not made in or supported with corporate colours. NR TSU website colours effectively transmit and support the visual image of the University. Visual accompaniment of the text content enhances the semantic component of the published materials. It is relevant to the specifics of information provided. 
The content analysis of the NR TSU website was carried out with the help of pr-cy.ru program. The following results have been obtained: the text length per page is significantly exceeded; it is about 39,615 symbols while 15,000 symbols is an upper limit recommended by search engine optimization (SEO) programmers. The number of words per page is 1,277 , which falls within the recommended range of 1,000 2,000 words. The number of keywords for natural search engine indexing is 194, which is excessive and does not correspond with the promotion policy.

An NR TSU page is "heavy" to download at $80 \mathrm{~KB}$, causing download speed to decrease. Keyword density is 8.154 words, compared to a recommended maximum of 7. This tendency indicates congestion of the text with key phrases on the official website. Indexes in the Yandex and Google search engines are approximately equal.

The content analysis of the website showed the lack of search engine optimization. The unique content shows the relevance of the pages to search queries, but the density rate of keywords, density size of pages, and other parameters for optimization are exceeded. The information on the homepage of the NR TSU website is presented in the form of inlays linked with additional internal websites of the University. Here the integration with other Internet platforms takes place. The internal structure of the inlays is detailed, and there is a possibility of expanding the internal information search. Inlays allow the user to "walk" through the website. However, the headings and subheadings are so detailed that it prevents users from finding needed information quickly. There is an opportunity to carry out an internal search for key relevant words on the website, but unless one requests the correct word, the needed information will not be found.

Requests for feedback on the website is offered as an opportunity to ask questions of the website administration by e-mail, to share news, to leave comments via social networks, or the opportunity to telephone the Information Department, as well as an opportunity to inform the site administrator about an error.

NR TSU is presented on the most active communication platforms of the web: Twitter, Facebook, LinkedIn, VKontakte. The photo and video content itself corresponds to the topics discussed in the community, which helps to create a complete image of the University.

2. The website of NR TPU (http://tpu.ru) contains all the elements of graphic visual communications. The website design is made mainly in green. Grey colour and a lighter shade of green are used as additional ones. The NR TPU logo is in form of the emblem with the date of the university establishment made in corporate colours. The website components constitute a common stylistic space.

The visualization is actively used on the website: many pictures, graphics and video. The use of these elements does not cause superfluity and forms a common visual space. The colours used on the NR TPU website transmit and support the image of the university. Visual support of the textual content is relevant to the provided information.

The content analysis of the website was carried out with the help of pr-cy.ru program. The following results were achieved: the text length per page is not exceeded, with 14,871 symbols when 15,000 symbols is the upper limit recommended by search engine optimization (SEO) programmers. The number of words per page is 482 (the maximum recommended number is $1,000-2,000$ words). The number of keywords for the best indexing of published materials in search engines is 71, which exceeds policy of promotion recommendations. Page size is "light" to download - $38 \mathrm{~KB}$, meaning the download speed is very fast. Keyword density is 6.6 words of the maximum allowable 7 , indicating potential congestion of the text on the NR TPU official website with key phrases. Indexes in Yandex and Google search engines reflect different results: the Yandex index is less than the Page Rank in the Google search engine.

The content analysis of the website has shown that it is optimized for search engines. The unique content shows the relevance of the pages to searches queries. The NR TPU website architecture is informative and structured, and the user can easily navigate back and forth through pages. Information on the official website of NR TPU is presented in the form of structured thematic inlays that enables the user to go conveniently to the page of interest. Information is localized according to various target audiences of the University. It is presented in the relevant sections in the form of built-in internal pages that provides a convenient search for information on a particular online resource. The website also contains the "Topic of the week" block, where the most up-to-date information is placed. A news block is located in the centre of the homepage of the official website, which functions as an internal site containing announcements and information about current events. There is an internal search feature for desired information, as well as a search within a corporate portal of NR TPU, for the internal public.

Feedback is provided through the users' opportunity to ask questions of the website administration by e-mail, to share news, to leave comments on social networks, or to call the Department of the Internet Communications or Public Relations Department. NR TPU is represented through the most active networking websites: Twitter, Facebook, LinkedIn, VKontakte. VKontakte is the most active among these platforms, having the official website and Instagram. Regular links to all the platforms provide the possibility for complete online communications. The feedback on the platform is weak. The photo and video content is relevant to actual events.

The communication audit of the university as a subject of electronic communications in a global network shows that the website is a key carrier and transmitter of its visual image. In cyberspace the website of the university is indeed a building with digital walls and foundation - open for a visit from any Internet user. Analysis of iconic signs of the websites' visual content shows that it is an image of the university building which serves as the base for the construction of its visual image. 
The sequence of images - academic buildings, library, research laboratories, and sport structures creates an image of the university that is able to serve a wide variety of its target audience's interests.

The use of the photos of university buildings in creation of its visual image reveals one more characteristic of the university's presence on the global network, which could be called "relocation" - the university moves to the Internet together with its infrastructure. Today we are witnesses the situation when an objective reality transforms into the information reality of signs. It means that by visiting the homepage of the university website we find ourselves in the "main building" - the centre of the university communication. When the university relocates to the global network, its life concentrates on the pages of the website - the official Internet representation. Moreover, it receives additional digital content because Internet communications having no time and space limits.

The visual image of the university constitutes its Internet representation from information and communication flows, and in reflecting different areas of its activities, such as: educational, research, cultural, and recreational. In terms of communication, the visual image focuses on targeting the widest public audiences, such as entrants, students, staff, academics, and experts. These factors determine semantic heterogeneity of visual image.

The analysis of the content of Tomsk universities' websites reveals dynamic and diverse life options for students, researchers, professors, and staff. We see that life at the University is "boiling": research projects, conferences, projects with partners - profit and nonprofit organizations, innovations in the learning process, festivals, competitions, meetings. As we have previously noted in the online communication audit, the user actually "walks" around the university by using references.

However, the "real virtuality" of M. Castells of the university is not limited to the website only. Internet technologies offer new ways and forms of social practice. University online communication include social media, publishing in mailing lists, registration in the catalogues of universities, interaction with the media on the Internet, regular monitoring of relevant forums and participation in them, and creation and coverage of events. One of the reasons for the extensive use of a visual image as a tool of communication by universities is their participation in the Webometrics ranking. It analyses the representation of the university in the Internet space and, thus, evaluates its research achievements. The need of presence in the world of electronic communications defines the direction of the universities' policies. Examples include the websites of the universities of Russia seeking to attain a place on the listing of the world's leading higher educational institutions, such as Moscow State University, Higher School of Economics; National Research Tomsk State University, National Research Tomsk Polytechnic University, and others (http://www.msu.ru; http: //www.hse.ru; http://tsu.ru; http://tpu.ru).

\section{Conclusion}

The university's website is one of the important elements in its modern communication structure. With its help, electronic communications penetrate into all areas of university life. The university website is multifunctional and deeply incorporated in social practice. The visual image designed and transmitted through the university website becomes the only media reality for the e-public. It is polysemantic and provides visual online communication of the university with its target audiences.

The effectiveness of the website as a generator of the visual image of a university can be evaluated by an online communication audit. By measuring the state of electronic communications of an organization with its external and internal audiences, the audit shows the status, image and position of the university in the information space. The structure of the online audit is made on the basis of the research objective and unique characteristics of the university.

Support and promotion of the visual image identifies the university on the web within the intensive competition in the marketplace for educational services, scientific research, and technological discoveries. Today, the visual image of the university becomes an indispensable tool for implementing online communication strategies of universities seeking to occupy a leading position in international rankings and to become a centre of excellence in science and education.

The visual image transmitted by the website not only "opens" the University for Internet users, it expands its institutional capacity. Communication platforms on the Internet, because of information saturation, multidimensional nature, interactivity, multi-media nature, and self-organization, allow a qualitatively different level - the level of virtuality - to carry out many university tasks.

\section{Acknowledgment}

We are grateful to the fourth-year students of Tomsk State University who joined us to explore the "Tomsk University on the Internet" theme. This discussion in workshops allowed us to clarify the specifics of the visual image of the modern university as promoted in the global network for various target audience. Interpretations are those of the authors. We thank the Russian Foundation for Humanities for grant № 14-1370005, "Tomsk Universities in the Communicative Space of the Internet: Positioning and Promotion", which facilitated the research and publication of results.

\section{References}

1. M. Castells, Galaktika Internet (2004) [The Internet Galaxy]. (In Russian) / Available at: http://filosof.historic.ru/books/item/f00/s01/z00010 24/st000.shtml Accessed 26 Jul 2015 
2. R. Barnett, Osmyslenie universiteta (1997) [Thinking the University]. (In Russian)/ Available at: http://charko.narod.ru/tekst/alm1/barnet.htm Accessed 26 Jul 2015

3. J.-F. Lyotard, Sostoyanie postmoderna [The Postmodern Condition]. Alteya (In Russian) (1998)

4. B. Readings, Universitet $\mathrm{v}$ ruinakh (2003) [The University in Ruins] (In Russian)/ Available at: URL:http://vk.com/doc184121870_244654672?has $\mathrm{h}=658 \mathrm{e} 56 \mathrm{~b} 02 \mathrm{e} 6 \mathrm{c} 437941 \& \mathrm{dl}=653822 \mathrm{e} 8 \mathrm{a} 83 \mathrm{dce} 156 \mathrm{~d}$ http://magazines.russ.ru/oz/2003/6/2004_1_16.html Accessed 26 Jul 2015

5. M. Prensky, Digital Natives, Digital Immigrants (2001) / Available at: http://www.marcprensky.com/writing/Prensky\%20$\% 20$ Digital $\% 20$ Natives, $\% 20$ Digital $\% 20$ Immigrants \%20-\%20Part1.pdf Accessed 26 Jul 2015

6. M. McLuhan, Galaktika Guttenberga: stanovlenie cheloveka pechatayushchego [The Gutenberg Galaxy: The Making of Typographic Man]. Akademicheskiy proekt (In Russian) (2005)

7. R. Shields, HIGHER EDUCATION, 71 (2), 253268 (2016)

8. G. Okushova, M. Bychkova, I. Guzhova, Positioning and Promotion of Tomsk Universities in the Internet Communicative Environment (Izdatelskiy dom TGU, 2014)

9. C. Greenhow, C. Lewin, LEARNING MEDIA AND TECHNOLOGY, 41 (1), 6-30 (2016) 